\title{
Monitoring of streptokinase resistance titre in acute myocardial infarction patients up to 30 months after giving streptokinase or anistreplase and related studies to measure specific antistreptokinase IgG
}

R Fears, H Ferres, E Glasgow, R Standring, K J Hogg, J D Gemmill, J M A Burns, A P Rae, F G Dunn, W S Hillis

\begin{abstract}
Objective-To examine the induction of antistreptokinase antibodies after giving streptokinase or anistreplase to patients with acute myocardial infarction.
\end{abstract}

Design-Patients were randomly allocated to receive either $1.5 \times 10^{6} \mathrm{IU}$, streptokinase or $30 \mathrm{U}$ anistreplase in a double blind study. Blood samples were collected immediately before treatment and subsequently at intervals up to 30 months; plasma samples were assayed for streptokinase resistance titre (functional assay) and streptokinase binding by IgG (microradioimmunoassay).

Setting-Cardiology department in a general hospital.

Patients-128 consecutive eligible patients. Samples were collected for up to one year according to a prospective design: a subsection of 47 patients was selected for intensive study over the first 14 days. After one year, all available patients (67) were sampled on one further occasion.

Results-Antibody responses to streptokinase and anistreplase were similar. Streptokinase resistance titres exceeded pretreatment concentrations five days after dosing, and values peaked at 14 days. By 12 months after dosing, $92 \%$ of resistance titres $(n=84)$ had returned to within the pretreatment range. Antistreptokinase IgG concentrations also exceeded baseline concentrations within five days and peaked at 14 days. Half of the individual values had returned to within the pretreatment range by 12 months $(n=84)$ and $89 \%$ by 30 months (n=18).

Conclusion-Although we cannot be sure of the clinical significance, because of the increased likelihood of resistance due to antistreptokinase antibody, streptokinase and anistreplase may not be effective if administered more than five days after an earlier dose of streptokinase or anistreplase, particularly between five days and 12 months, and increased antistreptokinase antibody may increase the risk of allergic-type reactions.

(Br Heart J 1992;68:167-70)
Varying concentrations of antibodies to streptokinase (SK) may be present in patients with acute myocardial infarction (AMI) as a result of previous streptococcal infections. ${ }^{12}$ The induction of anti-streptokinase (anti-SK) antibodies after the administration of SK or anistreplase (Eminase, APSAC) is, therefore, an anamnestic response. Previous studies on SK have measured the antibody response with a surrogate endpoint, the functional SK resistance titre, which also reflects the influence of inhibitors such as $\alpha_{2}$ antiplasmin and variations in other plasma proteins such as fibrinogen and plasminogen. ${ }^{1345}$ These studies have shown that a peak value was reached by two weeks after dosing with SK and returned towards pretreatment values by six months.

The development of neutralising antibodies may influence the efficacy and risk of an adverse reaction to $S K$ or anistreplase on readministration for a subsequent myocardial infarction, and in the context of the increasing use of thrombolytic therapy this might become an increasingly relevant clinical problem. It is therefore important to define the times of induction and decline in a population large enough to reflect the range of individual variations in neutralising antibody concentration. It was the purpose of the present work to compare changes in SK resistance titre in response to the standard doses of SK and anistreplase in patients with AMI. The results from this functional assay were compared with those from a novel method of assaying one antibody class (IgG) in terms of antigen binding. ${ }^{6}$

\section{Patients and methods}

PATIENTS

One hundred and twenty eight consecutive eligible patients ( 101 men, 27 women age range 31-70) were recruited between April 1987 and January 1989. Inclusion and exclusion criteria and adjunct treatments have been described previously. ${ }^{7}$ Patients were randomised in double blind, double dummy fashion to receive either $1.5 \times 10^{6} \mathrm{IU}$ SK infused intravenously over one hour or $30 \mathrm{U}$ anistreplase injected intravenously over five minutes. Initial patency, rates of reocclusion, and adverse events are described elsewhere. ${ }^{7}$ 
Evaluation of variations in streptokinase resistance titre after dosing with streptokinase or anistreplase

\begin{tabular}{lllllll}
\hline & \multicolumn{7}{l}{ Period of follow up (months with range) } \\
\cline { 2 - 7 } Analysis & 3 & 6 & $12(11-15)$ & $18(16-20)$ & $24(21-27)$ & $30(28-31)$ \\
\hline $\begin{array}{l}\text { Median evaluation as fold increase over } \\
\text { individual pretreatment value (n) }\end{array}$ & $20(39) \dagger$ & $15(38)$ & $4(60)$ & $5(22)$ & $2(20)$ & $2(18)$ \\
$\begin{array}{l}\text { Values (\%) returning to: } \\
\text { Within pretreatment range }\end{array}$ & & & & & & \\
Within 95th percentile pretreatment range & 51 & 72 & 92 & 100 & 100 & 100 \\
$\quad \begin{array}{l}\text { For all patients (n) } \\
\text { Theoretical neutralisation of streptokinase }\end{array}$ & $(45) \dagger$ & $(50)$ & $(84)$ & $(22)$ & $(26)$ & $(18)$ \\
$\quad(I U)$ (combining group median) & $1.2 \times 10^{6}$ & $1.2 \times 10^{6}$ & $6 \times 10^{5}$ & $3 \times 10^{5}$ & $3 \times 10^{5}$ & $3 \times 10^{5}$ \\
\hline
\end{tabular}

*Theoretical neutralisation by pretreatment median value $=1.5 \times 10^{5}$ (assuming a standard plasma volume of 31).

$\dagger$ Numbers of patients in the two types of analysis differ because median evaluation could only be calculated for those patients for whom pre and post treatment pairs of samples were available. At any one sampling time these pairs of samples are fewer than the total number of patients sampled.

Blood samples were collected from patients before dosing and serially at intervals for up to one year in a prospectively designed study. A subsection of 47 patients was selected for intensive study over the first 14 days although not all samples were received from each patient. Figures 1 and 3 show data from this cohort. The remaining figures and tables show available data for all patients. After one year all available patients (67) were sampled on one further occasion and these patients were grouped according to the classification described in the table.

\section{LABORATORY ASSESSMENTS}

The SK resistance titre and antiSK IgG concentrations were measured in individual plasma samples as described previously. ${ }^{6} \mathrm{Cal}-$ culations of the theoretical neutralisation of a second dose of SK were performed by multiplying the SK resistance titre by the average plasma volume of 3 litres.

\section{STATISTICAL ANALYSIS}

The SK resistance titres and anti-SK IgG concentrations, as analysed by either the WilkShapiro or the Kolmogorov-Smirnov test, were not normally distributed and so cannot be represented as arithmetic means. Values for SK resistance titres and for comparison IgG are shown as median values with ranges. The IgG values have also been analysed as geometric means as the log transformed values

Figure 1 Initial changes in $S K$ resistance titre. Values are shown as median and range for patients who received $S K$ (open bars) or anistreplase (stippled bars). Patient numbers are indicated $(n)$.

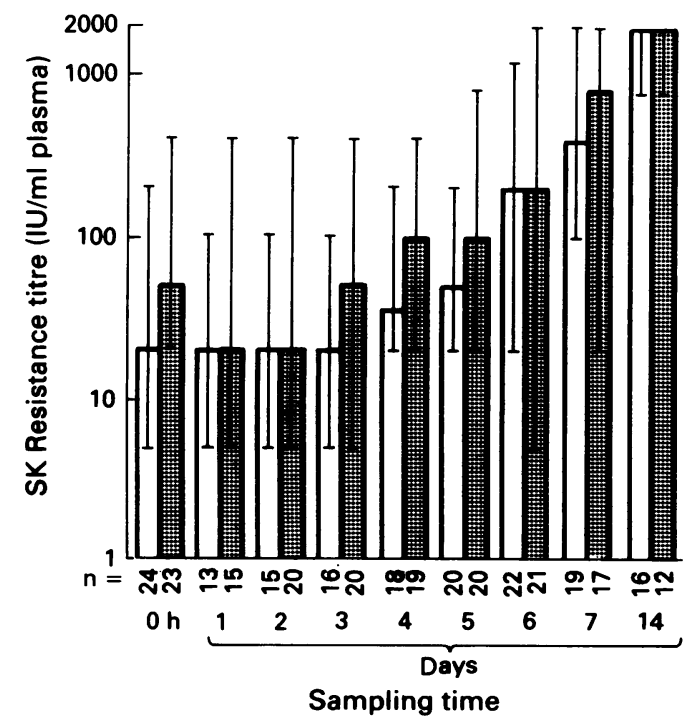

are normally distributed, and the conclusions are similar to those derived from a consideration of median values. The SK resistance and antiSK IgG results were analysed by the Mann-Whitney U test.

\section{Results}

SK RESISTANCE TITRE

Early serial changes (one to 14 days) were studied in detail in a subgroup of 47 patients. The response was similar whether patients were treated with SK or anistreplase, and baseline (pretreatment) values were consistently exceeded by five days after dosing (fig 1).

Figure 2 shows results for all patients, monitored up to 30 months. Measurements up to 12 months are serial analyses in the same patients (although a maximum of only 84 out of a possible 115 samples were collected in the prospectively designed study). By contrast, each patient was only sampled once over the period 12-30 months; that is, different patients appear in the groups collated at 18, 24, and 30 months and therefore groups are smaller at these times. Sampling times for the points within the period 12-30 months represent ranges: the total ranges are specified in the table.

Changes in SK resistance titre were similar for SK and anistreplase throughout the period of follow up (fig 2). Baseline (pretreatment) values however were significantly higher in the group of patients assigned to treatment with anistreplase (50 $v 20 \mathrm{IU} / \mathrm{ml}, \mathrm{p}<0.05)$.

Peak titres were reached two weeks after

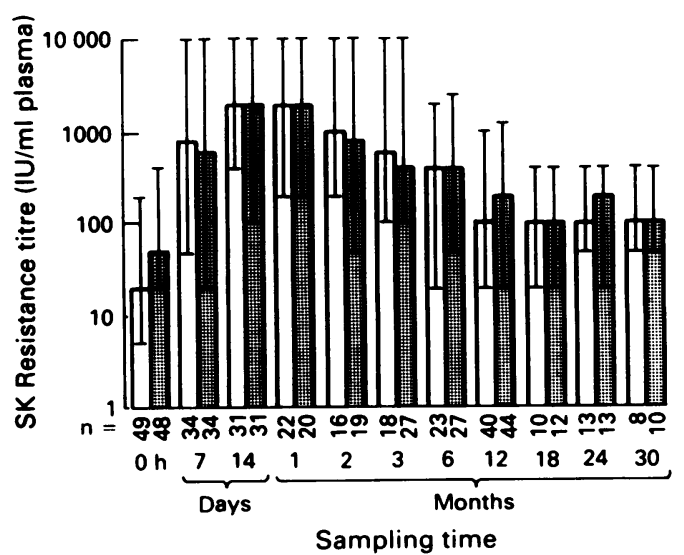

Figure 2 Changes in SK resistance titre up to 30 months. See legend to fig 1 for details. 
Figure 3 Initial changes in anti-SK IgG. See legend to fig 1 for details.

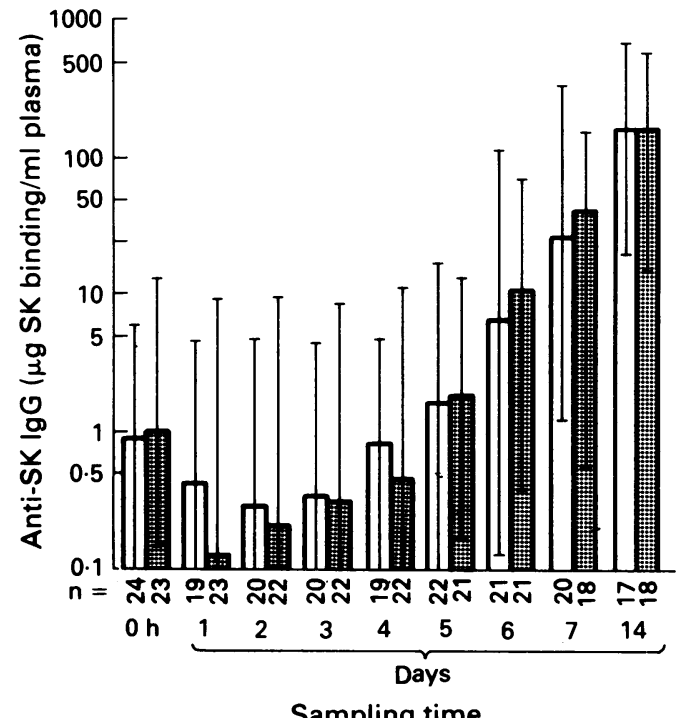

Sampling time

dosing (40 fold rise in median). Concentrations declined considerably by three to six months (fig 2), although the median rise above individual pretreatment concentrations was still noticeable for those patients in whom a complete set of data was collected (table). When examining all the data, it was seen that most individual values had returned to within the normal (pretreatment) range by six months, most values returned to within the 95th percentile of pretreatment range by 12 months (table). When the values for combined median SK resistance titre (as described in the methods) were used to calculate the theoretical neutralisation of a second dose of SK (assuming a standard plasma volume of 31 ) it was found that most of a standard dose $\left(1.5 \times 10^{6} \mathrm{IU}\right)$ might be neutralised up to six months but not thereafter.

\section{ANTISK IGG}

The early antiSK IgG response was also similar whether patients were treated with SK or anistreplase (fig 3). There was an initial fall in antiSK IgG in agreement with previous results $^{2}$ because of sequestration as the antibody antigen complex but, thereafter, values were restored to baseline by day 5 . This

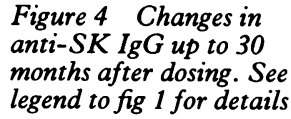

early fall in IgG (fig 3) is not accompanied by a similar decline in SK resistance titre (fig 1 ).

Figure 4 showed results for all patients monitored up to 30 months: changes in antiSK IgG were similar for SK and anistreplase throughout the period of follow up. It is noteworthy that baseline values are not higher in the patients assigned to anistreplase, unlike the situation with SK resistance titre (fig 2).

In agreement with the changes in SK resistance titre, peak values of anti-SK IgG were attained 14 days after dosing ( 150 fold rise in median). The subsequent decline in anti-SK IgG, however, seemed somewhat slower than the decline in SK resistance titre: $48 \%$ of individual anti-SK IgG values returned to within the normal range by 12 months after dosing (14\% at six months, $61 \%$ at 18 months, $65 \%$ at 24 months, and $89 \%$ at 30 months).

\section{Discussion}

We have shown already that the range of concentrations of anti-SK antibodies found in AMI populations before first treatmentwhether measured specifically as IgG or as the functional SK resistance titre-does not usually influence the thrombolytic efficacy of SK and anistreplase or the incidence of side effects. ${ }^{28}$ The concentration of antibody is usually low by comparison with the concentration required to bind all SK or anistreplase used, ${ }^{2910}$ and the inhibition of lysis is much less than the extent of binding. ${ }^{29}$

We have now shown that high values of neutralising antibody are rapidly induced after dosing with anistreplase and SK and the two agents seem to be indistinguishable. When measured in terms of the functional SK resistance titre, the present results confirm and extend previous findings, showing that most values return to within the normal range by six to 12 months. Extrapolating from group SK resistance titres to calculate how much of a second dose of SK might be neutralised, opinions on the possibility of readministration have varied from three months to greater than six months. ${ }^{1345}$ Our results suggest that much of a second standard dose $\left(1.5 \times 10^{6} \mathrm{IU}\right)$ of SK might be neutralised up to six months after the first dose but not at 12 months.

Our assay for specific anti-SK IgG is novel and these are the first results to define the rate of induction and decline after dosing with SK or anistreplase. The incremental change from baseline to two months appears similar to the preliminary results on $S K$ published recently for an enzyme linked immunosorbent assay (ELISA) method. ${ }^{11}$ The initial production of IgG, however, appeared to be more rapid when measured by ELISA than by radioimmunoassay in the present or a previous study. ${ }^{2}$ At the very high concentrations reached in the first few months, anti-SK IgG is a major contributor to the functional SK resistance titre. The fall in IgG during the first four days after treatment is not accompanied, however, by a reduction in SK resistance titre presumably because the fibrinolytic assay reflects the changes in fibrinogen, plasminogen, and $\alpha_{2}$-antiplasmin. The 
significantly higher baseline SK resistance titre in anistreplase treated patients and the poor correlation between changes in anti-SK IgG and SK resistance from three months onwards may also reflect contributions other than antiSK IgG, possibly $\alpha_{2}$ antiplasmin.

Anti-SK IgG antibodies have occasionally been implicated in adverse reactions after thrombolytic therapy with SK. ${ }^{11}$ In view of the very low incidence of severe allergic-type reactions in the large mortality trials of anistreplase $^{12}$ and SK, ${ }^{1314}$ however, it is not clear whether an appreciable risk is incurred when IgG is higher. The concentrations of anti-SK IgG in the few patients in our study who showed an allergic-like response ${ }^{7}$ were not appreciably different from the concentrations in patients without a response.

There are few publications on the size of the increment in clinically diagnosed allergic-type reactions in response to other antigens when IgG is raised. Work on dextrans indicates that most reactions seen when the IgG antibody titre increases beyond a range of 10 fold from the normal median are likely to be mild (grade I); more severe reactions require a much higher antibody concentration. ${ }^{15}$ Furthermore, although serious allergic type reactions are mediated by the complement pathway, complement is also lysed by plasmin in response to plasminogen activators such as alteplase. ${ }^{16}$ Therefore, complement activation and any contingent leucocyte attraction may occur regardless of the concentrations of anti-SK IgG.

In conclusion, we have defined the induction of neutralising antibodies to SK and anistreplase in AMI patients with the standard functional assay of $S K$ resistance titre. ${ }^{1345}$ The responses to anistreplase and SK are similar. Because of the increased likelihood of resistance due to anti-SK antibody, SK, and anistreplase may not be effective if administered more than five days after earlier SK or anistreplase particularly between five days and 12 months, and increased anti-SK antibody con- centrations may increase the risk of allergictype reactions.

We thank Drs E S Johnson, R Cregeen, and Mr S R Hasler for helpful discussions, Nadia James for typing the manuscript, and Julie Hearn for data entry.

1 Fletcher AP, Alkjaersig N, Sherry S. The maintenance of a sustained thrombolytic state in man. I. Induction and effects. J Clin Invest 1959;39:1096-110.

2 Hoffmann JJML, Fears R, Bonnier JJRM, Standring R, Ferres H, De Swart JBRM. Significance of antibodies to streptokinase in coronary thrombolytic therapy with streptokinase or APSAC. Fibrinolysis 1988;2:203-10.

3 Köstering H, Barth U, Naidu R. Changes of anti-streptokinase-titre following long term streptokinase therapy. In: Martin M, ed. New Concepts in Streptokinase Dosimetry. Huber, USA, 1978:110-5.

4 Massel D, Turpie AGG, Gill JB, Cairns JA, Russett J. Development of neutralizing antibodies after 1.5 million units of streptokinase in the treatment of acute myocardial infarction. Circulation 1989;80(suppl II):350.

5 Jalihal S, Morris GK. Antistreptokinase titres after intravenous streptokinase. Lancet 1990;335:184-5.

6 Moran DM, Standring R, Lavender EA, Harris GS. Assessment of anti-streptokinase antibody levels in human sera using a microradioimmunoassay procedure. Thromb Haemost 1985;52:281-7.

7 Hogg KJ, Gemill JD, Burns JMA, Lifson WK, Rae AP, Dunn FG, Hillis WS. Angiographic patency study of anistreplase versus streptokinase in acute myocardial infarction. Lancet 1990;335:254-8.

8 Gemmill JD, Hogg KJ, Burns JMA, Standring R, Greenwood H, Fears R, et al. Pre-treatment streptokinase (SK) resistance titres and anti-SK IgG levels are not related to hypotensive responses and coronary patency with SKcontaining thrombolytic agents. Br Heart J 1990;64:50-1.

9 Fears R, Ferres H, Hibbs M, Standring R. Consequences of antibody binding in vitro on the pharmacological properties of anisoylated plasminogen streptokinase activator complex. Drugs 1987;33(suppl 3):64-8.

10 Been M, de Bono DP, Muir AL, Boulton FE, Fears R, Standring R, Ferres H. Clinical effects and kinetic properties of intravenous APSAC-anisoylated plasminogenstreptokinase activator complex (BRL 26921) in acute streptokinase activator complex (BRL 26921) in
myocardial infarction. Int J Cardiol 1986;11:53-61.

11 Davies KA, Mathieson P, Winearls CG, Rees AJ, Walport MJ. Serum sickness and acute renal failure after streptokinase therapy for myocardial infarction. Clin Exp Immunol 1990;80:83-8.

12 AIMS Trial Study Group. Long-term effects of intravenous anistreplase in acute myocardial infarction: final report of the AIMS study. Lancet 1990;335:427-31.

13 GISSI. Effectiveness of intravenous thrombolytic treatment in acute myocardial infarction. Lancet 1986;1:397-402.

14 ISIS-2 Collaborative Group. Randomised trial of intravenous streptokinase, oral aspirin, both, or neither among 17187 cases of suspected acute myocardial infarction ISIS-2. Lancet 1988;2:349-60.

15 Richter AW, Hedin HI. Dextran hypersensitivity. Immunol Today 1982;3:132-8.

16 Bennett WR, Yawn DH, Migliore PJ, Young JB, Pratt CM, Raizner AE, et al. Activation of the complement system by recombinant tissue plasminogen activator. J Am Coll Cardiol 1987;10:627-32. 